\title{
The role and clinical significance of DNA damage response and repair pathways in primary brain tumors
}

\author{
Wil L Santivasi and Fen Xia*
}

\begin{abstract}
Primary brain tumors, in particular, glioblastoma multiforme (GBM), continue to have dismal survivability despite advances in treating other neoplasms. The goal of new anti-glioma therapy development is to increase their therapeutic ratios by enhancing tumor control and/or decreasing the severity and incidence of side effects. Because radiotherapy and most chemotherapy agents rely on DNA damage, the cell's DNA damage repair and response (DRR) pathways may hold the key to new therapeutic strategies. DNA double-strand breaks (DSBs) generated by ionizing radiation and chemotherapeutic agents are the most lethal form of damage, and are repaired via either homologous recombination (HR) or non-homologous end-joining (NHEJ) pathways. Understanding and exploitation of the differences in the use of these repair pathways between tumor and normal brain cells will allow for an increase in tumor cell killing and decreased normal tissue damage. A literature review and discussion on new strategies which can improve the anti-glioma therapeutic ratio by differentially targeting HR and NHEJ function in tumor and normal neuronal tissues is the focus of this article.
\end{abstract}

Keywords: Brain tumor, DNA repair, DNA damage, Homologous recombination (HR), Non-homologous end-joining (NHEJ)

\section{Introduction}

\section{Primary brain tumors}

In 2012, it is predicted that nearly 23,000 new primary brain tumors will be diagnosed, [1] of which $70 \%$ will be gliomas [2]. The most common type of glioma is glioblastoma multiforme (GBM), which accounts for $54 \%$ of all gliomas ( $42 \%$ of all primary brain tumors). Five-year survival is a dismal $4.70 \%$ for patients with GBM, [3] with a median survival time of just over 3 months following resection [4]. Despite a massive research effort, outcomes remain dismal in malignant brain tumors.

Our limited understanding of the mechanisms which underlie brain tumorigenesis severely limit preventative and therapeutic options for patients. The current standard treatment for GBM involves surgical resection followed by adjuvant radiotherapy (RT), with or without concomitant chemotherapy [5]. Disappointingly, this

\footnotetext{
*Correspondence: fen.xia@osumc.edu
Department of Radiation Oncology, The Ohio State University College of
Medicine, 072A Starling Loving Hall, 300 W. 10th Avenue, Columbus, OH

*Correspondence: fen.xia@osumc.edu
Department of Radiation Oncology, The Ohio State University College of
Medicine, 072A Starling Loving Hall, 300 W. 10th Avenue, Columbus, OH

* Correspondence: fen.xia@osumc.edu
Department of Radiation Oncology, The Ohio State University College of
Medicine, 072A Starling Loving Hall, 300 W. 10th Avenue, Columbus, OH 43210, USA
}

(c) 2013 Santivasi and Xia; licensee BioMed Central Ltd. This is an Open Access article distributed under the terms of the

regimen only affords GBM patients a median survival benefit of 14.6 months- a 12 month improvement over resection alone $[4,6]$. It is important to note that radioand chemotherapies are, at the molecular level, based on inducing enough DNA damage in the tumor cell to result in lethality. Unfortunately, these therapies also cause DNA damage to surrounding neuronal tissue, resulting in a variety of local and systemic toxicities. With regard to ionizing radiation (IR) treatments to the brain, side effects can be severe and include nausea, vomiting, seizure, and permanent cognitive and focal neurological deficits [7].

As such, there is a substantial research effort seeking to discover new therapeutic regimens that maximize tumor killing while minimizing these normal tissue toxicities, based on understanding of the differences in the behaviors and pathways of healthy and neoplastic cells. Current research and understanding of DNA damage response and repair (DRR) in glioma tumorigenesis and treatment response is the focus of this review. 


\section{DNA double-strand breaks (DSBs)}

A critical feature of the eukaryotic cell is its ability to maintain genome stability across generations, attributed, in part, to the sophisticated and precisely regulated DNA lesion-specific repair mechanisms. Deficiencies in DRR have been widely associated with a number of astrocytoma subtypes [8]. The pathways by which cells rectify DSBs are of particular note, as one unrepaired DSB can trigger apoptosis [9]. Erroneous repair of DSBs leads to gross genomic rearrangement, which can result in genomic instability and tumorigenesis. One example is the KIAA1549-RAF gene fusion generated by misrepair of DSBs found in pediatric astrocytomas [10]. As such, efficient and faithful DSB repair is critical to normal cell function and the prevention of neoplastic transformation in brain.

It has been well established that, in mammalian cells, DSBs are repaired through at least two distinct pathways: homologous recombination (HR) and nonhomologous end-joining (NHEJ). Both repair mechanisms have implications in tumorigenesis, impact tumor response to current treatment, as well as potentially serve as therapeutic targets in brain tumor management.

\section{Homologous recombination (HR)}

HR is a critical pathway for accurate repair of DSBs and maintenance of genomic stability. HR-mediated repair is characterized by deriving of the correct sequence from a homologous strand of intact DNA. This modeling process allows for high-fidelity repair of DSBs- much more so than repairs via NHEJ [11]. It is the primary pathway of DSB repair during the S and G2 phases of the cell cycle, in part due to the availability of sister chromatids to be used as repair templates [12].

HR mediated DSB repair follows a general scheme of nuclease-mediated resection of damaged DNA ends, polymerization of new DNA, and ligation to restore strand integrity. Detailed biochemistry of the pathway has been well described by others [13]. One of the important and well-studied proteins in the HR pathway is BRCA1, a tumor suppressor. BRCA1 serves as a "master controller" of HR, binding and regulating many downstream affectors including Mre11-Rad50-NBS1 (MRN) complex [14]. The MRN complex binds to DNA ends, and recruits nucleases, including Eme1, to clean up damaged bases and initiate the HR process $[15,16]$. The binding of MRN also activates ATM, which in turn phosphorylates and activates BRCA1 function in activating cell cycle checkpoints. This prevents the cell from entering mitosis before damage is repaired [17]. BRCA1 also indirectly interacts with the key HR effector protein Rad51. Rad51 and its paralogs such as XRCC3 are critical in homology searching to identify a homologous sequence on the sister chromatid [18,19]. When a homologous sequence is found, there is an exchange of the damaged strands, such that each strand is now paired with a homologous template. The damaged strands are then extended and ligated, restoring the original doublestrand $[20,21]$.

HR is a critical pathway for DSB repair fidelity. As such, dysregulation of HR processes resulting from functional deficiency of HR proteins has been associated with glioma development in many instances [8]. SNPs in the $\mathrm{XRCC} 3$ gene have been correlated with increased risk of glioma, [22,23] as have SNPs in BRCA1[24] and EME1 [25]. Identification of these risk SNPs and the mechanisms by which they increase glioma risk may provide novel targets for new therapies in the future.

\section{Therapeutic significance: induced HR deficiency mediates tumor sensitization to poly (ADP-ribose) polymerase 1 (PARP1) inhibition}

Given the replication demands in proliferating tumor cells, the HR pathway, which functions during S/G2, may be a valuable target for new and high-therapeutic index GBM treatment regimens. DNA single-strand breaks (SSBs) can lead to DSBs at the replication fork. Unrepaired DSBs are lethal to proliferating cells. Dysfunction in the repair of both SSBs and DSBs would be synthetically lethal. The enzyme poly(ADP-ribose) polymerase 1 (PARP1) plays a key role in the repair of SSBs, [26] while the tumor suppressor BRCA1 is essential for HR-mediated repair of DSBs $[27,28]$. PARP1 inhibitors, including Olaparib, target cancers which are deficient in the repair of DSBs, exhibit up to 1,000-fold selectivity in killing BRCA1-mutated (DSB-repair deficient) cells, and provide an overall survival and progression-free survival benefit with minimal toxicity in patients with BRCA1deficient familial breast cancer [29-33]. Unfortunately, the majorities of patients who develop sporadic tumors including malignant gliomas carry wild-type (wt) BRCA1 and are proficient in DSB repair, precluding them from this potent avenue of therapy [34]. We have previously shown that transiently exporting wt-BRCA1 protein from the nucleus (where DSBs are repaired) to the cytosol (where apoptosis is activated) makes cancer cells defective in the repair of DSBs [35]. We propose to develop an innovative therapeutic strategy that uses this export of BRCA1 from nucleus to cytoplasm to transiently convert BRCA1-proficient GBM cells into functionally BRCA1-deficient cells and thereby render them susceptible to PARP inhibitor-induced cell killing (Figure 1).

Experiments conducted in our laboratory have demonstrated proof of this concept in GBM cells. The HR pathway was inhibited by causing loss of BRCA1 function in three ways: (1) siRNA-mediated BRCA1 knockdown, (2) IR-mediated export of BRCA1 to the cytosol, 


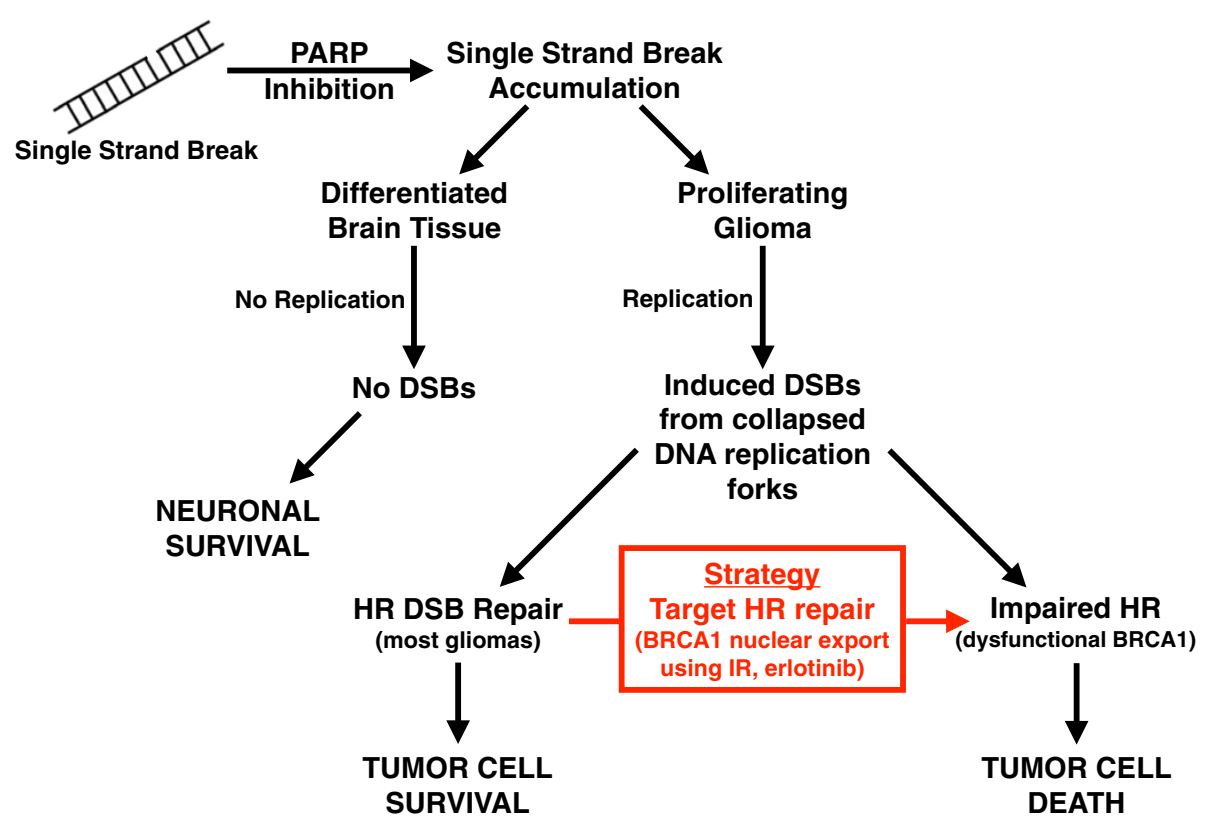

Figure 1 Targeting HR repair with poly (ADP-ribose) polymerase inhibition results in tumor-specific synthetic lethality. Model depicting potential targeting of HR repair to increase the therapeutic index of anti-glioma treatment. Sequestration of BRCA1 to the cytoplasm inhibits repair of DSBs and sensitizes cells to DNA-damaging agents. Following DNA damage, BRCA1 facilitates the repair of DNA in the nucleus. By targeting BRCA1 subcellular location, tumor cells retain unrepaired damaged DNA and are subsequently sensitized to poly (ADP-ribose) polymerase inhibitors.

and (3) erlotinib-induced BRCA1 nuclear depletion. siRNA-mediated BRCA1 knockdown results in suppression of HR repair in several cancer and non-cancer cell model systems. BRCA1 is also a nuclear-cytosolic shuttling protein, and its function is regulated by its subcellular location. When in the nucleus, BRCA1 participates in HR repair of DSBs. When in the cytosol, it enhances apoptosis. We have recently found that IR induces nuclear export of BRCA1 in response to DNA damage via the CRM1/exportin-dependent pathway. Additionally, inhibition of EGFR by erlotinib results in DNA damage and BRCA1 nuclear export [36]. In all three instances, HR-mediated DSB repair was attenuated, and tumor cytotoxicity response to the PARP inhibitor ABT-888 was significantly increased versus non-HR-inhibited controls. By inducing tumor-specific HR deficiencies, we believe that PARP inhibitor therapy will result in more efficacious, safer treatment of both HR-deficient and HR-competent tumors.

\section{Non-homologous End-joining (NHEJ)}

While HR provides some genomic protection, NHEJ is another major DSB repair pathway in mammalian cells. In contrast to HR, NHEJ repairs on a wide variety of DSBs with distinct break structures and sequences [37] and functions predominantly during G1 when the HR repair is not available [38]. However, it demonstrates decreased fidelity compared to HR, as NHEJ repairs
DSBs using no or little homologous template to ensure that the repaired strand reflects the original sequence [39].

Similarly to the HR process, NHEJ repair follows a basic motif of damaged base digestion, re-polymerization/repair, and ligation. Its details have been well-characterized by others [39]. Briefly, following identification of the DSB by the cell, Ku70 and Ku80 bind to the exposed breakpoints as a heterodimer and serve to recruit other necessary proteins [40]. DNA-dependent protein kinase (DNA-PK) is recruited to the site and exposes the DNA ends to recruited nucleases [41,42]. DNA-PK also activates the G1 DNA damage checkpoint and arrests the G1-S transition [43]. A wide variety of nucleases digest nucleotides from the DNA on both strands, and strand re-extension is facilitated by X family DNA polymerases, [44] although in a less extensive fashion than occurs in HR [11]. Finally, the DNA ligase IV complex joins the two repaired DNA ends [45].

Due to NHEJ's role as a DNA repair system and checkpoint activator, it is no surprise that there appears to be a connection between its malfunction and tumorigenesis in the brain. SNP variations in several NHEJ genes, including those that code for the DNA ligase IV complex, [46] Ku80 and Ku70, [47] and DNA-PK's catalytic subunit [24] have been correlated with increased risk of glioma. Furthermore, loss of DNA-PK function has been demonstrated to increase IR resistance in GBM 
cells [48]. Despite these implications, it may be possible to exploit the tumor's NHEJ deficiency in planning treatment strategies.

\section{Therapeutic significance: NHEJ potentiation mediates IR neuroprotection}

While proliferating tumor cells can repair DSBs through both HR during S/G2 and NHEJ during G1, differentiated normal neuronal cells largely rely on NHEJ to survive from DSBs [37,49]; Thus, exploration of the difference in regulation of NHEJ activities in GBM versus normal neurons may provide neuronal protection from IR-induced cytotoxicity without affording the same benefit to tumor cells, thereby improving therapeutic gain. One promising target is glycogen synthase kinase $3 \beta$ (GSK3 $\beta$ ), which regulates glucose metabolism by phosphorylating glycogen synthase and inhibits glycogen synthesis. Interestingly, we and others have recently demonstrated that GSK3 $\beta$ is also involved in suppression of NHEJ activity [50]. Furthermore, inhibition of GSK3 $\beta$ either genetically or by its specific inhibitors (lithium or SB216763) accelerates NHEJ-mediated DSB repair and protects hippocampal neurons from IR-induced apoptosis via restoration of DNA-PK-dependent NHEJ repair of DNA DSBs, [51] and attenuates neuro-cognitive toxicity in mice. Most importantly, this GSK3 $\beta$-mediated radioprotection does not occur in glioma cells examined in the studies [51-53].

The differential effect on NHEJ and radiation protection in normal neuron versus tumor cells may be attributed to following: (1) GSK3 $\beta$ is constitutively expressed at high level in differentiated cells but not expressed in proliferating cells, [54] (2) additional inhibition of GSK3 $\beta$ activity in proliferating tumor cells. $40 \%$ of primary gliomas demonstrate loss of phosphatase and tensin homo$\log$ (PTEN) function [55]. Canonically, PTEN inhibits the action of AKT, which in turn inhibits GSK3 $\beta$ [56]. As such, loss of PTEN function and /or increased AKT activity in tumor cells results in strong suppression in GSK3 $\beta$ activity. While most gliomas demonstrate markedly decreased GSK3 $\beta$ function, [57] lithium or SB216763 will not be able to generate significant modification in GSK3 $\beta$-NHEJ activity as in normal neuronal cells. Together, these findings have demonstrated that the difference in GSK3 $\beta$-mediated NHEJ regulation between healthy neural tissue and glioma cells can be exploited to benefit the patient, and have provided strong preclinical evidence and rational for clinical implementation of GSK3 $\beta$ inhibition in combination with standard GBM treatment (Figure 2).

\section{Future directions}

Current therapies for primary brain gliomas are not effective in tumor control and often cause severe and deleterious neruo-congnitive and systemic toxicities. It is urgent to develop novel treatment with significantly improved therapeutic gains. By utilizing the strategies outlined above, it is possible to exploit differences between tumors' and CNS cells' DRR pathways, specifically their DSB repair mechanisms. An increased therapeutic ratio can be accomplished by either tumor-specific sensitization (BRCA1 nuclear export and HR attenuation) or by neuron-specific radioprotection (GSK3 $\beta$ inhibition and NHEJ potentiation). As we proceed toward

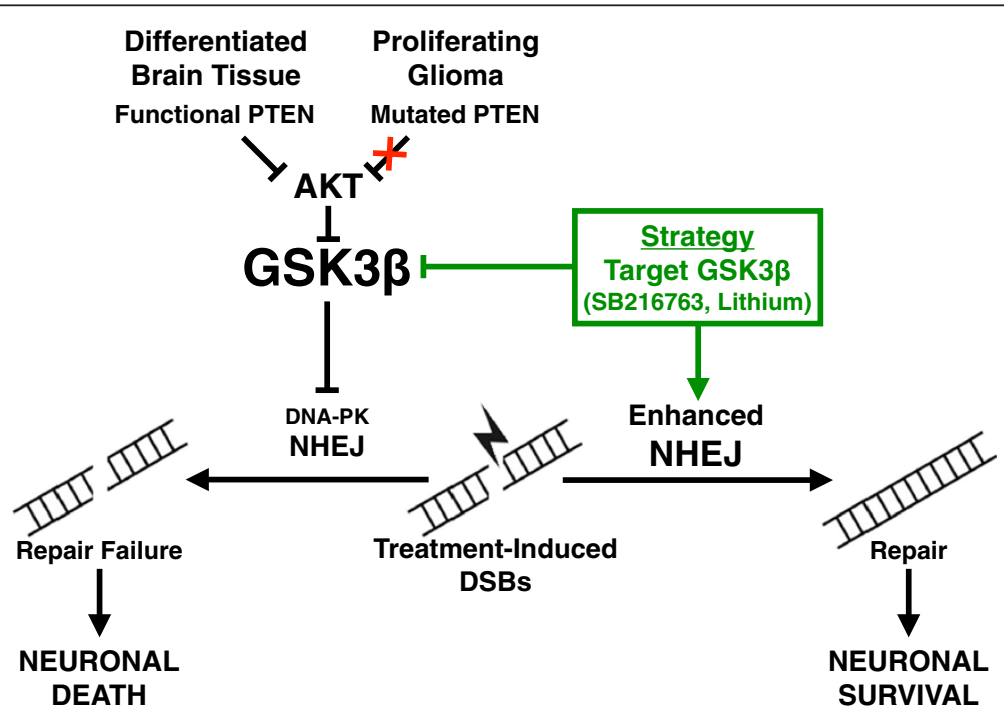

Figure 2 Targeting GSK3 $\beta$ results in neuroprotection from IR-induced neurotoxicity. Model depicting potential targeting of GSK3 $\beta$-NHEJ signaling pathway to decrease neurotoxicity and increase the therapeutic index of anti-glioma treatment. Inhibition of GSK3 $\beta$ results in the upregulation of DNA-PK dependent NHEJ repair in neural but not tumor cells. By targeting GSK3 $\beta$, neurons, but not GBM cells, gain enhanced DNA repair functionality, and therefore protected from IR-induced neuronal cell death. 
genetics-driven, individualized cancer therapeutics, a deep understanding of the DRR pathways will become even more important, as they will likely harbor new treatment targets and provide new insights into how tumorigenesis occurs in the brain.

\section{Competing interests}

The authors declare that they have no competing interests.

\section{Authors' contributions}

WLS \& FX participated in the literature search. WLS drafted the manuscript. FX edited the manuscript. All authors read and approved the final manuscript.

Received: 22 August 2012 Accepted: 6 December 2012

Published: 6 February 2013

\section{References}

1. Siegel R, Naishadham D, Jemal A: Cancer statistics, 2012. CA Canc J Clin 2012, 62:10-29.

2. Ohgaki H: Epidemiology of brain tumors. In Cancer Epidemiology. Edited by Verma M, Totowa NJ. New York: Humana Press; 2009:323-342 [Walker JM (Series Editor): Methods in Molecular Biology, vol 472.]

3. CBTRUS Statistical Report: Primary Brain and Central Nervous System Tumors Diagnosed in the United States in 2004-2008 (March 23, 2012 Revision). Hinsdale, IL: Source: Central Brain Tumor Registry of the United States; 2012.

4. Tran B, Rosenthal MA: Survival comparison between glioblastoma multiforme and other incurable cancers. J Clin Neurosci 2009, 17:417-421.

5. Batchelor T, Curry WT: Clinical manifestations and initial surgical approach to patients with malignant gliomas. In UpToDate. Edited by Loeffler JS, Waltham MA. Philadelphia: Wolters Kluwer Health; 2012.

6. Van Meir EG, Hadjipanayis CG, Norden AD, Shu HK, Wen PY, Olson JJ: Exciting new advances in neuro-oncology: the avenue to a cure for malignant glioma. CA Canc J Clin 2010, 60:166-193.

7. Lawrence YR, Li XA, el Naga I, Hahn CA, Marks LB, Merchant TE, Dicker AP: Radiation dose-volume effects in the brain. Int J Rad Onc 2010, 76:s20-s27.

8. Gu J, Liu Y, Kyritsis AP, Bondy ML: Molecular epidemiology of primary brain tumors. Neurotherapeutics 2009, 6:427-435.

9. Frosina G: DNA repair and resistance of gliomas to chemotherapy and radiotherapy. Mol Canc Res 2009, 7:989-999.

10. Lawson AR, Hindley GF, Forshew T, Tatevossian RG, Jamie GA, Kelly GP, Neale GA, Ma J, Jones TA, Ellison DW, Sheer D: RAF gene fusion breakpoints in pediatric brain tumors are characterized by significant enrichment of sequence homology. Genome Res 2011, 21:505-514.

11. Mao Z, Bozzella M, Seluanov A, Gorbunova V: Comparison of nonhomologous end joining and homologous recombination in human cells. DNA Repair (Amst) 2008, 7:1765-1771.

12. Alberts B, Johnson A, Lewis J, Raff M, Roberts K, Walter P: Molecular Biology of the Cell. 5th edition. Oxford: Garland Science; 2008

13. Moynahan ME, Jasin M: Mitotic homologous recombination maintains genomic stability and suppresses tumorigenesis. Nat Rev Mol Cell Biol 2010, 11:196-207.

14. Powell SN, Kachnic LA: Roles of BRCA1 and BRCA2 in homologous recombination, DNA replication fidelity and the cellular response to ionizing radiation. Oncogene 2003, 22:5784-5791.

15. Uziel T, Lerenthal Y, Moyal L, Andegeko Y, Mittelman L, Shiloh Y: Requirement of the MRN complex for ATM activation by DNA damage. EMBO J 2003, 22:5612-5621.

16. Miyagawa K: Clinical relevance of the homologous recombination machinery in cancer therapy. Canc Sci 2008, 99:187-194.

17. Bucher N, Britten CD: G2 checkpoint abrogation and checkpoint kinase-1 targeting in the treatment of cancer. Brit J Canc 2008, 98:523-528.

18. Zou Y, Liu Y, Wu X, Shell SM: Functions of human replication protein A (RPA): from DNA replication to DNA damage and stress responses. J Cell Phys 2006, 208:267-273.

19. Brenneman MA, Wagener BM, Miller CA, Allen C, Nickoloff JA: XRCC3 controls the fidelity of homologous recombination. Mol Cell 2002, 10:387-395.
20. Maloisel L, Fabre F, Gangloff S: DNA polymerase delta is preferentially recruited during homologous recombination to promote heteroduplex DNA extension. Mol Cell Biol 2008, 28:1373-1382.

21. Goetz JD, Motycka TA, Han M, Jasin M, Tomkinson AE: Reduced repair of DNA double-strand breaks by homologous recombination in a DNA ligase I-deficient human cell line. DNA Repair (Amst) 2005, 4:649-654.

22. Zhou K, Liu Y, Zhang H, Liu H, Fan W, Zhong Y, Xu Z, Jin L, Wei Q, Huang F, Lu D, Zhou L: XRCC3 haplotypes and risk of gliomas in a Chinese population: a hospital-based case-control study. Int J Canc 2009, 124:2948-2953.

23. Kiuru $A$, Lindholm $C$, Heinavaara $S$, Ilus $T$, Jokinen $P$, Haapasalo $H$, Salminen T, Christensen HC, Feychting M, Johansen C, Lonn S, Malmer B, Schoemaker $\mathrm{MJ}$, Swerdlow AJ, Auvinen A: XRCC1 and XRCC3 variants and risk of glioma and meningioma. J Neuro Oncol 2008, 88:135-142.

24. Wang L, Bondy ML, Shen H, El-Zein R, Aldape K, Cao Y, Pudavalli V, Levin VA, Yung WK, Wei Q: Polymorphisms of DNA repair genes and risk of glioma. Canc Res 2004, 64:5560-5563.

25. Chang JS, Yeh RF, Wiencke JK, Wiemels JL, Smirnov I, Pico AR, Tihan T, Patoka J, Miike R, Sison JD, Rice T, Wrensch MR: Pathway analysis of singlenucleotide polymorphisms potentially associated with glioblastoma multiforme susceptibility using random forests. Canc Epidemiol Biomarkers Prev 2008, 17:1368-1373.

26. Ame JC, Spenlehauer C, de Murcia G: The PARP superfamily. Bioessays 2004, 26:882-893

27. Zhang J, Willers H, Feng Z, Ghosh JC, Kim S, Weaver DT, Chung JH, Powell SN, Xia F: Chk2 phosphorylation of BRCA1 regulates DNA double-strand break repair. Mol Cell Biol 2004, 24:708-718.

28. Gudmundsdottir $\mathrm{K}$, Ashworth A: The roles of BRCA1 and BRCA2 and associated proteins in the maintenance of genomic stability. Oncogene 2006, 25:5864-5874

29. Farmer $\mathrm{H}$, McCabe N, Lord CJ, Tutt AN, Johnson DA, Richardson TB, Santarosa M, Dillon K, Hickson I, Knights C, Martin NM, Jackson SP, Smith GC, Ashworth A: Targeting the DNA repair defect in BRCA mutant cells as a therapeutic strategy. Nature 2005, 434:917-921.

30. Bryant HE, Schultz N, Thomas HD, Parker KM, Flower D, Lopez E, Kyle S, Meuth M, Curtin NJ, Helleday T: Specific killing of BRCA2-deficient tumours with inhibitors of poly(ADP-ribose) polymerase. Nature 2005, 434:913-917.

31. Turner NC, Lord CJ, lorns E, Brough R, Swift S, Elliott R, Rayter S, Tutt AN, Ashworth A: A synthetic lethal siRNA screen identifying genes mediating sensitivity to a PARP inhibitor. EMBO J 2008, 27:1368-1377.

32. Fong PC, Boss DS, Yap TA, Tutt A, Wu P, Mergui-Roelvink M, Mortimer $P$, Swaisland H, Lau A, O'Connor MJ, Ashworth A, Carmicheal J, Kaye SB, Schellens $J H$, de Bono JS: Inhibition of poly(ADP-ribose) polymerase in tumors from BRCA mutation carriers. N Engl J Med 2009, 361:123-134.

33. Underhill $\mathrm{C}$, Toulmonde $\mathrm{M}$, Bonnefoi $\mathrm{H}$ : A review of PARP inhibitors: from bench to bedside. Ann Oncol 2011, 22:268-279.

34. Banerjee S, Kaye S: PARP inhibitors in BRCA gene-mutated ovarian cancer and beyond. Curr Oncol Rep 2011, 13:442-449.

35. Wang H, Yang ES, Jiang J, Nowsheen S, Xia F: DNA damage-induced cytotoxicity is dissociated from BRCA1's DNA repair function but is dependent on its cytosolic accumulation. Canc Res 2010, 70:6258-6267.

36. Li L, Wang H, Yang ES, Arteaga CL, Xia F: Erlotinib attenuates homologous recombinational repair of chromosomal breaks in human breast cancer cells. Canc Res 2008, 68:9141-9146.

37. Lieber MR, Ma Y, Pannicke U, Schwarz K: Mechanism and regulation of human non-homologous DNA end-joining. Nat Rev Mol Cell Biol 2003, 4:712-720.

38. Shibata A, Conrad S, Birraux J, Geuting V, Barton O, Ismail A, Kakarougkas A, Meek K, Taucher-Scholz G, Lobrich M, Jeggo PA: Factors determining DNA double-strand break repair pathway choice in G2 phase. EMBO J 2011, 30:1079-1092

39. Weterings $E$, Chen $D J$ : The endless tale of non-homologous end-joining Cell Res 2008, 18:11-124.

40. Spagnolo L, Rivera-Calzada A, Pearl LJ, Llorca O: Three-dimensional structure of the human DNA-PKcs/Ku7-/Ku80 complex assembled on DNA and its implications for DNA DSB repair. Mol Cell 2006, 22:511-519.

41. Moll U, Lau R, Sypes MA, Gupta MM, Anderson CW: DNA-PK, the DNA-activated protein kinase, is differentially expressed in normal and malignant human tissues. Oncogene 1999, 18:3114-3126.

42. Ma Y, Pannicke U, Schwarz K, Lieber MR: Hairpin opening and overhang processing by an artemis/DNA-dependent protein kinase complex in nonhomologous end joining and V(D)J recombination. Cell 2002, 108:781-794. 
43. Suzuki K, Kodama S, Watanabe M: Recruitment of ATM protein to double strand DNA irradiated with ionizing radiation. J Biol Chem 1999, 274:25571-25575.

44. Yamtich J, Sweasy JB: DNA polymerase family X: function, structure, and cellular roles. Biochim Biophys Acta 2010, 1804:1136-1150.

45. Wilson TE, Grawunder U, Lieber MR: Yeast DNA ligase IV mediates nonhomologous DNA end joining. Nature 1997, 388:495-498.

46. Liu Y, Zhou K, Zhang H, Shugart YY, Chen L, Xu Z, Shong Y, Liu H, Jin L, Wei Q, Huang F, Lu D, Zhou L: Polymorphisms of LIG4 and XRCC4 involved in the NHEJ pathway interact to modify risk of glioma. Hum Mutat 2008, 29:381-389.

47. Liu Y, Zhang H, Zhou K, Chen L, Xu Z, Zhong Y, Liu H, Li R, Shugart YY, Wei Q, Jin L, Huang F, Lu D, Zhou L: Tagging SNPs in non-homologous end-joining pathway genes and risk of glioma. Carcinogenesis 2007, 28:1906-1913.

48. Burma S, Chen DJ: Role of DNA-PK in the cellular response to DNA double-strand breaks. DNA Repair 2004, 3:909-918.

49. Iliakis G, Wang H, Perrault AR, Boecker W, Rosidi B, Windhofer F, Wu W, Guan J, Terzoudi G, Pantelias G: Mechanisms of DNA double strand break repair and chromosome aberration formation. Cytogenet Genome Res 2004, 104:14-20

50. Doble BW, Woodgett JR: GSK-3: tricks of the trade for a multi-tasking kinase. J Cell Sci 2003, 116:1175-1186.

51. Yang ES, Wang H, Jiang G, Nowsheen S, Fu A, Hallahan DE, Xia F: Lithium-mediated protection of hippocampal cells involves enhancement of DNA-PK-dependent repair in mice. J Clin Invest 2009, 119:1124-1135.

52. Yazlovitskaya EM, Edwards E, Thotala D, Fu A, Osusky KL, Whetsell WO, Boone B, Shinohara ET, Hallahan DE: Lithium treatment prevents neurocognitive deficit resulting from cranial irradiation. Canc Res 2006, 66:11179-11186.

53. Yang ES, Nowsheen S, Wang T, Thotala DK, Xia F: Glycogen synthase kinase $3 \beta$ inhibition enhances repair of DNA double-strand breaks in irradiated hippocampal neurons. Neuro Oncol 2011, 13:459-470.

54. Liang J, Slingerland JM: Multiple roles of the PI3K/PKB (Akt) pathway in cell cycle progression. Cell Cycle 2003, 4:339-345.

55. Knobbe CB, Merlo A, Reifenberger G: Pten signaling in gliomas. Neuro Oncol 2002, 4:196-211.

56. Paez J, Sellers W: PI3K/PTEN/Akt pathway: a critical mediator of oncogenic signaling. In Signal Transduction in Cancer. Edited by Walker JM. Boston, MA: Springer Press; 2004:145-167.

57. Korur S, Huber RM, Sivasankaran B, Petrich M, Morin P, Hemmings BA, Merlo A, Lino MM: GSK3 $\beta$ Regulates Differentiation and Growth Arrest in Glioblastoma. PLoS One 2009, 4:e7443.

doi:10.1186/2045-3701-3-10

Cite this article as: Santivasi and Xia: The role and clinical significance of DNA damage response and repair pathways in primary brain tumors. Cell \& Bioscience 2013 3:10.

\section{Submit your next manuscript to BioMed Central and take full advantage of:}

- Convenient online submission

- Thorough peer review

- No space constraints or color figure charges

- Immediate publication on acceptance

- Inclusion in PubMed, CAS, Scopus and Google Scholar

- Research which is freely available for redistribution 